\title{
Self-selection of diets with different oil oxidation levels in gilthead seabream
}

\section{(Sparus aurata)}

\author{
A. Montoya ${ }^{\text {a }}$, D. Alves Martins ${ }^{\text {b, c }}$, M. Yúfera ${ }^{c}$, F.J. Sánchez-Vázquez ${ }^{\mathrm{a}, *}$, \\ ${ }^{a}$ Departament of Physiology, Faculty of Biology, University of Murcia, 30100 Murcia, \\ Spain \\ ${ }^{\text {b } C e n t r o ~ d e ~ C i e ̂ n c i a s ~ d o ~ M a r ~ d o ~ A l g a r v e, ~ U n i v e r s i t y ~ o f ~ A l g a r v e, ~ C a m p u s ~ d e ~ G a m b e l a s, ~}$ \\ 8005-139 Faro, Portugal \\ ${ }^{\mathrm{c}}$ Instituto de Ciencias Marinas Andalucía (CSIC), Apartado Oficial, 11510 Puerto Real, \\ Cádiz, Spain
}

Running title: Dietary oxidised oil selection in sea bream

*Author to whom request for reprints should be addressed:

Dr. F.J. Sánchez-Vázquez

Department of Physiology, Faculty of Biology,

University of Murcia, 30100 Murcia, Spain

Tel: + 34-868-884931

Fax: + 34-868-883963

E-mail:javisan@um.es 


\section{ABSTRACT}

The present research looked at the ability of gilthead seabream to discriminate between two similar diets differing only in the extent of lipid oxidation. Six groups of 4 fish (254g initial wet weight) were allowed to select by means of self-feeders between two complete diets $(34.5 \%$ casein + gelatin, $14.8 \%$ fish oil + soybean oil, $24.8 \%$ dextrin and 25.9\% vitamins, minerals, filler and binder) which differed only in the oxidation level of the lipid source: $6.2 \mathrm{meq} / \mathrm{kg}$ for the control (D1) and $100.0 \mathrm{meq} / \mathrm{kg}$ for the oxidized diet (D2). During the first nine days of the trial, fish took similar amounts of D1 and D2, although there was a clear tendency to gradually avoid D2. Finally, on day 10 fish demanded a significantly higher percentage (82\%) of D1. When the diets were intercharged to investigate feeder preferences, two selection patterns were observed: three groups resumed their selection for D1 from day 7 onwards, while the other three groups did not show a clear preference for any diet until they were subjected to a 3week fasting period (which boosts internal oxidation), after which they significantly selected D1. Taken together the results before and after fasting, gilthead seabream were able to discriminate and avoid a diet with oxidised lipids, and the physiological state of fish (oxidative stress caused by fasting) appeared to reinforce their selection/avoidance behaviour.

Keywords: gilthead seabream; self-feeding; oxidised lipids 


\section{INTRODUCTION}

"Nutritional wisdom" in animals has been described as an ability to select the nutrients that best suit to their nutritional requirements. In this sense, diet selection is used as a tool to investigate animals’ preference from a range of foods (Forbes, 1995). In fish, a variety of experiments have examined their feeding preferences for macronutrients (Sánchez-Vázquez et al., 1999, Aranda et al, 2000, Vivas et al., 2006), and the capacity of several fish species to self-select a nutritionally balanced diet has been demonstrated. Furthermore, the capacity of fish to discriminate diets differing in their amino acid profile (Yamamoto et al., 2000) or different dietary oils (Pettersson et al., 2009; Fortes-Silva et al., 2010) has recently been reported. However, the ability of fish to discriminate between diets containing the same oil source but with different degrees of oxidation remains unexplored.

Despite their high quality, marine lipids such as fish oil are susceptible to oxidation due to the high content of HUFA of the $n$-3 series (Bimbo and Crowther, 1992). Fish oil oxidation results in an increase of the oxygen radicals and in a decrease in the $\alpha$-tocopherol content (Koshio et al., 1994), both being key factors involved in the oxidative processes. Therefore, the aim of this research was to investigate the capacity of gilthead seabream, an important marine species in Mediterranean aquaculture, to discriminate and avoid the noxious effects of feeding with an oxidised oil source.

\section{MATERIALS AND METHODS}

\section{Fish and experimental/stocking conditions}

A total of 24 seabream (254 g initial mean body wet weight) were distributed among six 150-l tanks supplied with filtered, sterilized and aerated sea water of around $25^{\circ} \mathrm{C}$. The photoperiod was set at $12 \mathrm{~h}$ light: $12 \mathrm{~h}$ dark (regular LD cycle) by an 
electronic timer. During the first week of acclimation, before testing the experimental diets, fish were fed a commercial gilthead seabream feed (D-4 EXCELL 2-P, Skretting) by self-feeders. Each tank was equipped with two self-feeders, operated by fish without restrictions through string sensors placed below the water surface (Rubio et al., 2004). The amount of food demanded but not consumed was registered daily during the whole experimental period in order to estimate the average daily food intake.

The fish were offered simultaneously two diets that varied only in their degree of oxidation. Each self-feeder dispensed one diet so that the fish could select a diet of both. Once the dietary selection had stabilized, to check that dietary selection was guided only by stimuli generated by food ingestion, the position of the self-feeders was exchanged and the experiment continued until the dietary selection had re-stabilized.

\section{Diet Manufacturing}

The composition of the experimental diets D1 and D2 is given in Table 1. Both diets were almost identical, differing only in the degree of oxidation of the lipids they contained. A mixture of visceral pollock and soybean oil was oxidized according to Koshio et al. (1994) by bubbling oxygen while stirring and heating at $50^{\circ} \mathrm{C}$. The oxidation degree was monitored by determination of the peroxide value at $8 \mathrm{~h}$ intervals. The mixture was moistened by adding water, pelleted by forcing through a garlic press and cut into about $5 \mathrm{~mm}$ length pellets. The pellets were freeze-dried and stored in a freezer until use. Dietary moisture was determined by drying samples for $24 \mathrm{~h}$ at $110^{\circ} \mathrm{C}$, crude protein was estimated by micro-Kjeldahl ( $\mathrm{N}$ x 6.25), crude fat was extracted with diethyl ether according to the SOXTEC system and ash was determined by heating at $450^{\mathrm{a} C}$ for $24 \mathrm{~h}$. 


\section{Statistical analysis}

Percentages of daily food demand were normalised by arcsin transformation and analyzed using a paired Students' t-test. Differences in average food intake between groups were analyzed using one-way ANOVA. Differences in the average daily food intake and feed wastage between experimental phases were analyzed using paired t-test. Significant differences were considered when $\mathrm{p}<0.05$.

\section{RESULTS AND DISCUSSION}

Average daily food intake was $1.57 \pm 0.20 \%$ body weight and remained stable throughout the trials. Feed wastage did not show significant differences between experimental phases ( $>0.05$, paired t-test). When D1 and D2 were simultaneously available through self-feeders, fish gradually learnt to avoid D2, showing statistically significant differences $(\mathrm{p}<0.05)$ as regards their preference $(82 \%)$ for D1 from day 9 onwards (Fig. 1). However, when the diets were shifted to test possible feeder preferences, only 3 out of the 6 groups resumed their selection of D1 from day 7 onwards. The remaining groups did not show a clear preference for any particular diet. However, when these 3 groups were subjected to a 3-week fasting period, fish significantly selected D1 5 days after refeeding.

In order to discriminate between diets, fish use different pre-ingestive signals, such as food characteristics (odour, taste) or feeder position, and post-ingestive signals, such as metabolic effects. In our experiment, the fact that different responses were observed after changing the position of the feeders, suggested that both pre- and postingestive signals are involved in diet selection. The fact that fish needed a certain period of time (around one week) to discriminate and avoid the oxidised diet suggested that post-ingestive signals are the key factors. These results agree with a previous study 
carried out in Atlantic salmon (Hamre et al., 2001) which reported that fish only slightly avoided an oxidised diet when it was offered for the first time, suggesting that fish may tolerate high levels of oxidation products before an avoidance response is built up due to their noxious effects.

The effects of feeding fish with dietary oxidised oil have been reported, with a 34 fold TBARS increase being observed in the plasma of salmon (Hamre et al., 2001) and liver of Tilapia (Huang and Huang, 2004), and increased activity of the hepatic antioxidant defence enzymes in gilthead seabream (Mourente et al., 2002). In addition, a study carried out in seabream reported that the activities of antioxidant defence enzymes increased significantly in parallel with food restriction (Pascual et al., 2003). Therefore, internal oxidation caused by fasting together with a previous intake of D2 may explain why gilthead seabream quickly learnt to avoid D2 following a fasting period.

In short, this study provides the first evidence that fish, given the choice to select through self-feeders, refuse an oxidised diet in order to avoid its noxious effects, with the internal physiological state of fish playing a key role in their selection behaviour.

\section{REFERENCES}

Alves Martins, D., Afonso L.O.B., Hosoya, S., Lewis-MCcrea L.M., Valente L.M. P., Lall S.P. 2007. Effects of moderately oxidized dietary lipid and the role of vitamin $\mathrm{E}$ on the stress response in Atlantic halibut (Hippoglossus hippoglossus L.). Aquaculture 272: 573-580.

Aranda, A., Sánchez-Vázquez, F.J., Zamora, S., Madrid, J.A., 2000. Self-design of fish diets by means of self-feeders: validation of procedures. J. Physiol. Biochem. 56, 155-166. 
Bimbo, A.P., Crowther, J.B., 1992. Fish meal and oil current uses. J. Am. Oil Chem. Soc. 69, 221-227.

Forbes, J.M., 1995. Diet Selection. In: Forbes, J.M. editor. Voluntary Food Intake and Diet Selection in Farm Animals. Cab International, Wallingford, UK, p.277303.

Fortes-Silva, R., Martínez, F.J., Villarroel, M., Sánchez-Vázquez, F.J., 2010. Daily feeding patterns and self-selection of dietary oil in Nile tilapia. Aquac. Res. 42, 157-160.

Geurden, I., Corraze, G., Boujard, T., 2007. Self-feeding behavior of rainbow trout, Oncorhynchus mykiss, offered diets with distinct feed oils. Appl. Anim. Behav. Sci. 108, 313-326.

Hamre, K., Kolås, K., Sandnes, K., Julshamn, K., Kiessling, A., 2001. Feed intake and absortion of lipid oxidation products in Atlantic salmon (Salmo salar) fed diets coated with oxidised fish oil. Fish Physiol. Biochem. 25, 209-219.

Huang, C.-H., Huang, S.-L., 2004. Effect of dietary vitamin E on growth, tissue lipid peroxidation, and liver glutathione level of hybrid juvenile tilapia, Oreochromis niloticus × O.aureus, fed oxidized oil. Aquaculture 237, 381-389.

Koshio, S., Ackman, R.G., Lall, S.P., 1994. Effects of oxidized herring and canola oils in diets on growth, survival and flavor of Atlantic salmon, Salmo salar. J. Agric. Food Chem. 42, 1164-1169.

Miglavs, I., Jobling, M., 1989. The effects of feeding regime on proximate body composition and patterns of energy deposition in juvenile artic charr, Salvelinus alpinus. J. Fish Biol. 35, 1-11.

Mourente, G., Díaz-Savago, E., Bell, J.G., Tocher, D.R., 2002. Increased activities of hepatic antioxidant defence enzymes in juvenile gilthead seabream (Sparus 
aurata, L.) fed dietary oxidised oil: attenuation by dietary vitamin E. Aquaculture 214, 343-361.

Pascual, P., Pedrajas, J.R., Toribio, F., López-Barea, J., Peinado, J., 2003. Effect of food deprivation on oxidative stress biomarkers in fish (Sparus aurata). Chem-Biol Interact. 145, 191-199.

Pettersson, A., Johnsson, L., Brännäs, E., Pickova, J., 2009. Effects of rapeseed oil replacement in fish feed on lipid composition and self-selection by rainbow trout (Oncorhynchus mykiss). Aquacult. Nutr. 15, 577-586.

Rubio, V.C., Vivas, M., Sánchez-Mut, A., Sánchez-Vázquez, F.J., Covés, D., Dutto, G., Madrid, J.A., 2004. Self-feeding of European sea bass (Dicentrarchus labrax, L.) under laboratory and farming conditions using a string sensor. Aquaculture 233, 392-403.

Sánchez-Vázquez, F.J., Yamamoto, T., Akiyama, T., Madrid, J.A., Tabata, M., 1998. Macronutrient self-selection through demand feeders in rainbow trout. Physiol. Behav. 66, 45-51.

Vivas, M., Rubio, V.C., Sánchez-Vázquez, F.J., Mena, C., García García, B. Madrid, J.A., 2006. Dietary self-selection in sharpsnout seabream (Diplodus puntazzo) fed paired macronutrients feeds and challenged with protein dilution. Aquaculture 251, 430-437.

Yamamoto, T., Shima, T., Furuita, H., Shiraishi, M., Sánchez-Vázquez, F.J., Tabata, M., 2000. Self-selection of diets with different amino acid profiles by rainbow trout (Oncorhynchus mykiss). Aquaculture 187, 375-386. 


\section{FIGURE LEGENDS}

Figure 1. Evolution of diet selection. Black circles represent the percentage of selection (mean \pm S.E.M) of the oxidised diet (D2), whereas open circles indicate the percentage of selection (mean \pm S.E.M) of the non-oxidised diet (D1). Asterisks indicate statistically significant differences (paired t-test, $\mathrm{p}<0.05$ ) in the diet selection percentages of both diets.

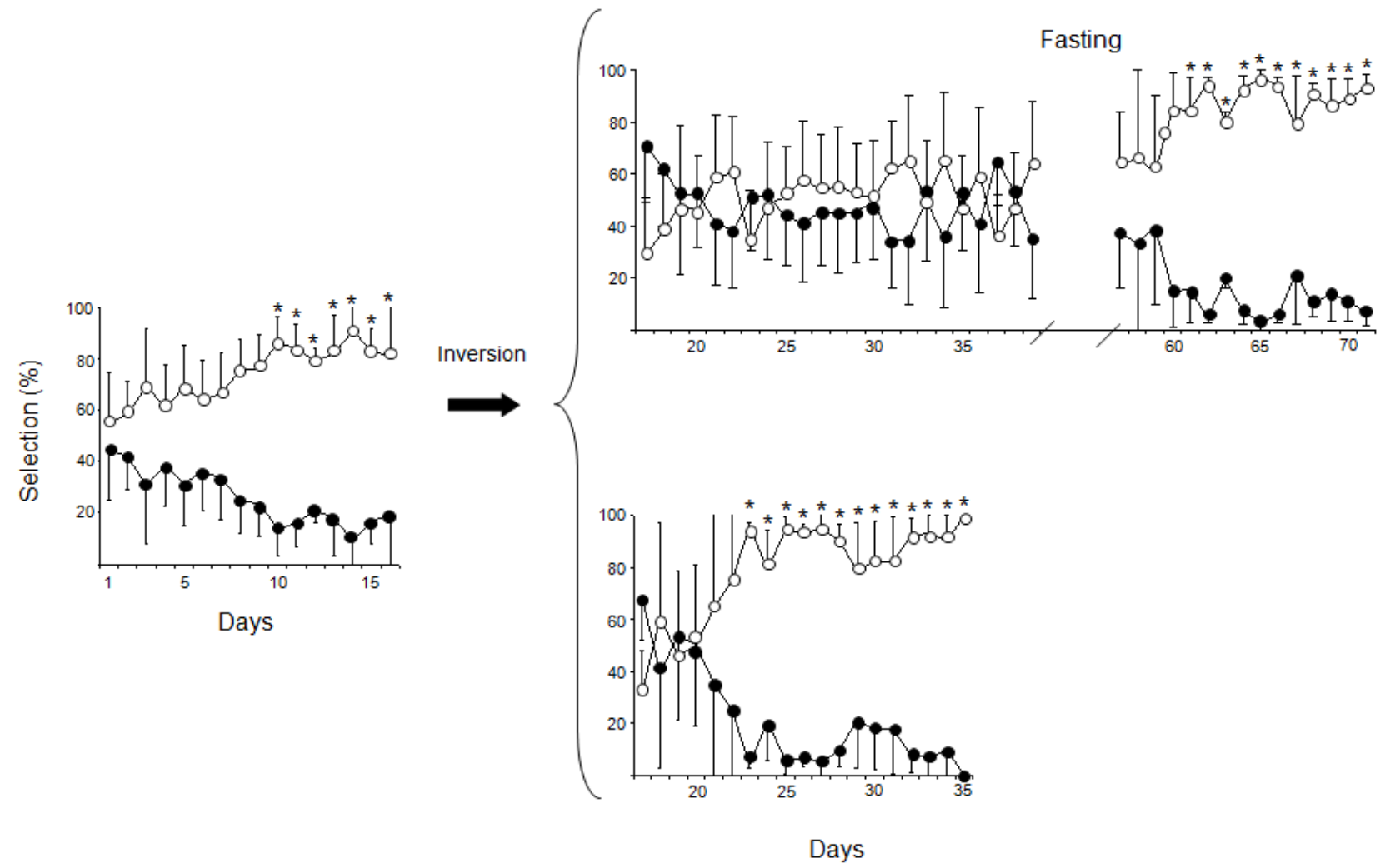

Figure 1 
Table 1. Formulation and proximate composition of the experimental diets.

$$
\text { control oxidised }
$$

\begin{tabular}{|c|c|c|}
\hline \multicolumn{3}{|l|}{ Ingredients ( $\mathrm{g} / 100 \mathrm{~g}$ of diet) } \\
\hline Casein: gelatin $(6: 1)$ & 34.53 & 34.53 \\
\hline Dextrin & 24.87 & 24.87 \\
\hline Oil mixture ${ }^{a}$ & 14.85 & - \\
\hline Oxidised oil mixture ${ }^{b}$ & - & 14.85 \\
\hline $\mathrm{C}_{\mathrm{a}} \mathrm{CO}_{3} / \mathrm{C}_{\mathrm{a}} \mathrm{PO}_{4}(1: 1)$ & 4 & 4 \\
\hline Cellulose & 15.5 & 15.5 \\
\hline Sodium alginate & 4.5 & 4.5 \\
\hline Vitamin and mineral mixture ${ }^{c}$ & 1.75 & 1.75 \\
\hline \multicolumn{3}{|l|}{ Proximate composition (\% DM) } \\
\hline Crude protein $(\mathrm{N} \times 6,25)$ & 32.13 & 32.13 \\
\hline Crude fat & 15.79 & 15.79 \\
\hline Ash & 4.98 & 4.98 \\
\hline Moisture & 7.16 & 7.16 \\
\hline 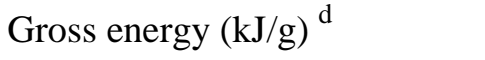 & 18.08 & 18.08 \\
\hline \multicolumn{3}{|l|}{ Oil oxidation } \\
\hline Peroxide value & 6.18 & 100 \\
\hline
\end{tabular}

${ }^{\mathrm{a}}$ Cod liver oil: soybean oil (3:1)

${ }^{\mathrm{b}}$ Cod liver oil: soybean oil (3:1) oxidised by bubbling with oxygen while heating and stirring until POV=100 meq kg -1

${ }^{\mathrm{C}}$ Composition of vitamin mineral mix: vitamin A, 1000000 (I.U./Kg diet); vitamin D3, 150000 (I.U./Kg diet); vitamin E, 30000 (I.U./Kg diet); vitamin B1, 1600 (I.U./Kg diet); vitamin B2, 3200 (I.U./Kg diet); vitamin B6, 3200 (I.U./Kg diet); vitamin B12, 2,4 (I.U./Kg diet); vitamin C, 15000 (I.U./Kg diet); vitamin K, 1000 (I.U./Kg diet); dPantotenate, 9600 (I.U./Kg diet); Folic Acid, 600 (I.U./Kg diet); Niacin, 12000 (I.U./Kg diet); Biotin, 28 (I.U./Kg diet); Betain, 80000 (I.U./Kg diet); $\mathrm{CuSO}_{4} .5 \mathrm{H}_{2} \mathrm{O}, 1$ (g/kg diet), FeCO3, 8 (g/kg diet), $\mathrm{MnO}_{2}, 3$ (g/kg diet), $\mathrm{ZnO} 2,18$ (g/kg diet), IK 0,4 (g/kg diet). mec kg -1

${ }^{\mathrm{d}}$ Calculated from the macronutrient percentage mean using the following energy coefficients: $23.6 \mathrm{~kJ} / \mathrm{g}$ for protein; $38.9 \mathrm{~kJ} / \mathrm{g}$ for fat; and $16.7 \mathrm{~kJ} / \mathrm{g}$ for carbohydrate (Miglavs and Jobling, 1989) 